\title{
Studi Perbandingan Kinerja Model Transmisi TwoRayGround dan Nakagami pada OLSR di Lingkungan MANET Menggunakan NS-2
}

\author{
Dhiya'an Sabila Ramadhani, Radityo Anggoro \\ (ITS) \\ Jl. Arief Rahman Hakim, Surabaya 60111 Indonesia \\ e-mail: onggo@if.its.ac.id
}

Jurusan Teknik Informatika, Fakultas Teknologi Informasi, Institut Teknologi Sepuluh Nopember

\begin{abstract}
Abstrak-Perangkat mobile seperti notebook, handphone, tablet dan lain lain mulai berkembang adanya teknologi nirkabel (wireless) saat ini yang menjadi indikator kemajuan peradaban manusia memungkinkan perangkat komunikasi dapat berkomunikasi secara langsung dengan perangkat lainnya dalam posisi bergerak dan tanpa adanya jaringan infrastruktur yang tetap dan bersifat sementara, jaringan semacam ini disebut sebagai MANET (Mobile Ad Hoc Network). Dalam MANET, setiap node bergerak secara bebas, sehingga jaringan dapat mengalami perubahan topologi dengan cepat. Karena node dalam MANET memiliki jarak transmisi yang terbatas, beberapa node tidak bisa berkomunikasi secara langsung dengan node lainnya. Maka dari itu, pada studi perbandingan ini yang diteliti adalah skema MANET yang dihasilkan oleh file node-movement dan trafficpattern yang telah ada pada distribusi network simulator. Penelitian ini menggunakan NS-2 sebagai network simulator dengan protokol proaktif MANET jenis OLSR (Optimized Link State Protocol) sebagai protokol routing yang digunakan serta menggunakan model transmisi TwoRayGround dan Nakagami sebagai pembanding yang ada pada NS-2. Hasil dari pengujian adalah suatu perbandingan performa dari model transmisi TwoRayGround dan Nakagami pada protokol routing OLSR di lingkungan MANET dengan menggunakan NS-2.
\end{abstract}

Kata Kunci-MANET, Nakagami, Network Simulator, NS-2, OLSR, TwoRayGround.

\section{PENDAHULUAN}

$\mathrm{S}$ EIRING dengan perkembangan zaman, teknologi informasi berkembang dengan pesat dan kebutuhan masyarakat akan komunikasi sehingga mengakses informasi pun semakin mudah. Perangkat mobile seperti notebook, handphone, tablet mulai berkembang adanya teknologi nirkabel (wireless) saat ini yang menjadi indikator kemajuan peradaban manusia memungkinkan perangkat komunikasi dapat berkomunikasi secara langsung dengan perangkat lainnya dalam posisi bergerak dan tanpa adanya jaringan infrastruktur yang tetap dan jaringan semacam ini disebut Mobile Ad Hoc Network (MANET).

Dalam MANET, setiap node bergerak secara bebas, sehingga jaringan dapat mengalami perubahan topologi dengan cepat. Karena node dalam MANET memiliki jarak transmisi yang terbatas, beberapa node tidak bisa berkomunikasi secara langsung dengan node lainnya. Pada MANET, jalur routing mengandung beberapa hop dan setiap node berfungsi sebagai router untuk menentukan ke arah mana tujuan atau rute yang akan mereka pilih. Dalam menentukan setiap jalur routing pada MANET terdapat tiga jenis protokol routing yang diklasifikasikan menjadi tiga, diantaranya protokol routing proactive, reactive dan hybrid. Pada protokol routing proactive akan terus mempelajari perubahan topologi secara real-time melalui node jaringan tetangganya. Oleh karena itu, setiap ada permintaan rute dari node sumber ke node tujuan, informasi routing tersebut sudah tersedia pada node sumber. Seiring dengan perubahan topologi jaringan, akan dapat terjadinya peningkatan keseluruhan biaya pemeliharaan jaringan [1].

Implementasi pada lingkungan MANET dapat dilakukan dengan menggunakan simulasi sehingga penelitian ini dapat dilakukan untuk mempelajari sistem dengan baik. Simulasi dilakukan dengan menggunakan Network Simulator 2 (NS-2). Implementasi ini akan dilakukan analisa performa protokol routing proactive yaitu Optimized Link State Routing (OLSR). Pada kasus ini menggunakan model transmisi TwoRayGround dan Nakagami digunakan sebagai pembanding yang ada pada NS-2. Hasil dari penelitian ini adalah suatu perbandingan model transmisi TwoRayGround dan Nakagami pada protokol routing OLSR di lingkungan MANET dengan menggunakan aplikasi. Performa protokol routing tersebut diukur berdasarkan routing overhead, packet delivery ratio, dan delay pengiriman paket dari node ke node lainnya.

\section{TINJAUAN PUSTAKA}

\section{A. Mobile Ad Hoc Network (MANET)}

Mobile Ad Hoc Network (MANET) adalah kumpulan dari beberapa wireless node yang dapat di-set-up secara dinamis dimana saja dan kapan saja, tanpa menggunakan infrastruktur jaringan yang ada. MANET juga merupakan jaringan sementara yang dibentuk oleh beberapa mobile node tanpa adanya pusat administrasi dan infrastruktur kabel. Pada MANET, mobile host yang terhubung dengan wireless dapat bergerak bebas dan juga berperan sebagai router. MANET memiliki beberapa karakteristik yaitu di antaranya konfigurasi jaringan yang dinamis, bandwidth yang terbatas, keterbatasan daya untuk tiap-tiap operasi, keterbatasan keamanan dan setiap node pada MANET berperan sebagai end-user sekaligus sebagai router yang menghitung sendiri route-path yang selanjutnya akan dipilih [2]. 


\section{B. Optimized Link State Routing (OLSR)}
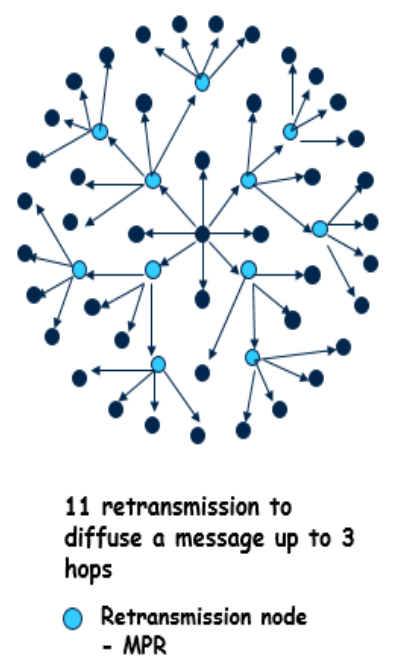

Gambar 1Proses Packet Flooding pada OLSR [3]

OLSR merupakan protokol routing proaktif, yang dapat dengan segera menyediakan routing ke semua network tujuan yang ada. Protokol ini merupakan pengembangan dari algoritma link-state klasik untuk memenuhi persyaratan dari jaringan nirkabel dinamis seperti MANET. OLSR merupakan protokol routing yang menggunakan algoritma link-state klasik dan algoritma Djikstra untuk mencari shortest path. Optimalisasi ini berdasarkan pada konsep Multipoint Relays (MPR). Setiap node menyeleksi node-node tetangganya sebagai Multipoint Relay (MPR). Pada OLSR, hanya node yang berperan sebagai MPR yang bertanggung jawab untuk melanjutkan control traffic (paket kontrol), yang dimaksud untuk penyebaran ke seluruh jaringan. Multipoint Relays (MPRs) menyediakan mekanisme untuk melakukan flood control traffic dengan mengurangi jumlah transmisi yang dibutuhkan [3].

\section{Model Transmisi TwoRayGround}

Dalam mobile radio channel, single direct path antara base station dan mobile terkadang hanya peralatan fisik biasa untuk propagasi dan rumus pada free space kurang akurat jika dalam penggunaannya berdiri sendiri. Model transmisi TwoRayGround merupakan model yang berguna karena berdasar pada optik geometri dan dapat digunakan untuk direct path dan refleksi dari ground antara transmitter dan receiver. Model ini dirasa sangat akurat untuk memperkirakan kekuatan sinyal dalam skala luas dengan jarak beberapa kilometer untuk sistem mobile radio dengan menggunakan menara yang tinggi. Power yang diterima dengan jarak d diberikan oleh persamaan Error! Reference source not found.:

$$
P_{r}(d)=\frac{P_{t} G_{t} G_{r} h_{t}^{2} h_{r}^{2}}{d^{4} L}
$$

dimana $\mathrm{P}_{\mathrm{t}}$ adalah power yang ditransmisikan, $\mathrm{G}_{\mathrm{t}}$ dan $\mathrm{G}_{\mathrm{r}}$ adalah tegangan antena pada transmitter dan receiver, $h_{t}$ dan $h_{r}$ adalah tinggi dari antena transmitter dan receiver, nilai L diasumsikan sama dengan nilai $\mathrm{L}$ pada propagasi free space, $\mathrm{L}=1$. Untuk parameter yang lain, masih sama dengan parameter pada propagasi free space. Berdasarakan rumus matematika diatas, power loss lebih cepat hilang dibandingkan dengan rumus matematika pada model propagasi free space ketika jaraknya bertambah. Namun, Model ini tidak memberikan hasil yang baik untuk jarak yang terlalu dekat dikarenakan osilasi yang disebabkan oleh konstruktif dan destruktif yang merupakan kombinasi dari model ini [4].

\section{Model Transmisi Nakagami}

Artikel yang siap untuk dipublikasikan harus dilengkapi dengan sebuah formulir copyright. Model Nakagami-m-m bersifat lebih umum dan dapat diterapkan untuk berbagai kondisi fading, tergantung pada parameter-m yang digunakan. Kanal Nakagami-m-m memiliki probability density function (PDF) yang dinyatakan sebagai persamaan Error! Reference source not found. [5].

$$
P_{R}(R)=\frac{2 m^{m} R^{2 m-1}}{\Gamma(m) \Omega^{m}} \exp \left(-\frac{m R^{2}}{\Omega}\right), R \geq 0
$$

dimana :

$\mathrm{m}=$ parameter fading,$\quad \mathrm{m} \geq 0.5$ sampai $\sim$ (integer positif)

$\mathrm{R}=$ amplitudo fading

$\Gamma=$ fungsi gamma

$\Omega=\mathrm{E}\left[\mathrm{R}^{2}\right]$

Pengaruh parameter-m pada kanal Nakagami-m-m:

1. Apabila $m \leq 1$, maka persamaan Error! Reference source not found. menjadi probabilitas density function dari kanal fading Rayleigh.

2. Apabila $m>1$, merujuk ke kanal fading Ricean. Dimana kanal fading Ricean memiliki faktor $\mathrm{K}$ yang memiliki pengaruh disini. Sehingga nilai $\mathrm{m}$ adalah sebagai persamaan Error! Reference source not found. [5].

$$
m=\frac{(1+k)^{2}}{1+2 k}, k \geq 0
$$

\section{E. Network Simulator 2 (NS-2)}

Network Simulator 2 (NS-2) merupakan alat simulasi jaringan yang bersifat open source yang banyak digunakan dalam mempelajari struktur dinamik dari jaringan komunikasi. Simulator ini ditargetkan pada penelitian jaringan dan memberikan dukungan yang baik untuk simulasi routing, protokol multicast dan protokol IP, seperti UDP, TCP, RTP, jaringan nirkabel dan jaringan satelit. Beberapa keuntungan menggunakan network simulator sebagai perangkat lunak simulasi yaitu network simulator dilengkapi dengan tools validasi, pembuatan simulasi dengan menggunakan network simulator jauh lebih mudah daripada menggunakan software developer seperti Delphi atau $\mathrm{C}++$, network simulator bersifat open source di bawah GPL (Gnu Public License) dan dapat digunakan pada sistem operasi Windows dan sistem operasi Linux [6]. 


\section{ANALISIS DAN PERANCANGAN}

\section{A. Analisis Permasalahan}

Terdapat beberapa permasalahan utama yang diangkat dalam pembuatan Tugas Akhir ini. Pertama adalah bagaimana kinerja protokol routing OLSR pada MANET. Permasalahan kedua adalah bagaimana perbandingan kinerja model transmisi TwoRayGround dan Nakagami pada OLSR di lingkungan MANET.

\section{B. Deskripsi Umum}

Pada Tugas Akhir ini dilakukan analisis tentang performa model transmisi TwoRayGround dan Nakagami pada MANET. Dalam pembuatan skenario MANET yaitu dengan cara mengenerate file node-movement (mobility-generation) dan membuat koneksi antar node menggunakan file trafficconnection pattern. Dalam penelitian ini, terdapat 2 jenis model transmisi yang digunakan sebagai perbandingan pengukuran performa dari pengiriman data antar node yaitu model transmisi TwoRayGround dan Nakagami. Kemudian untuk simulasi skenario yang dihasilkan oleh mobility generator akan dijalankan pada NS-2 menggunakan protokol routing OLSR pada sistem operasi Linux.

Pada tiap skenario, kecepatan maksimum pergerakan dari satu node ke node lainnya dibuat bervariasi yaitu 5, 10 dan 15 $\mathrm{m} / \mathrm{s}$. Hasil proses uji coba dari tiap skenario akan menghasilkan sebuah trace file yang nantinya akan dilakukan analisis perhitungan metrik Packet Delivery Ratio (PDR), End-to-End Delay (E2D), dan Routing Overhead (RO). Dari hasil metrik tersebut dianalisis performa kedua model transmisi yang dibandingkan.

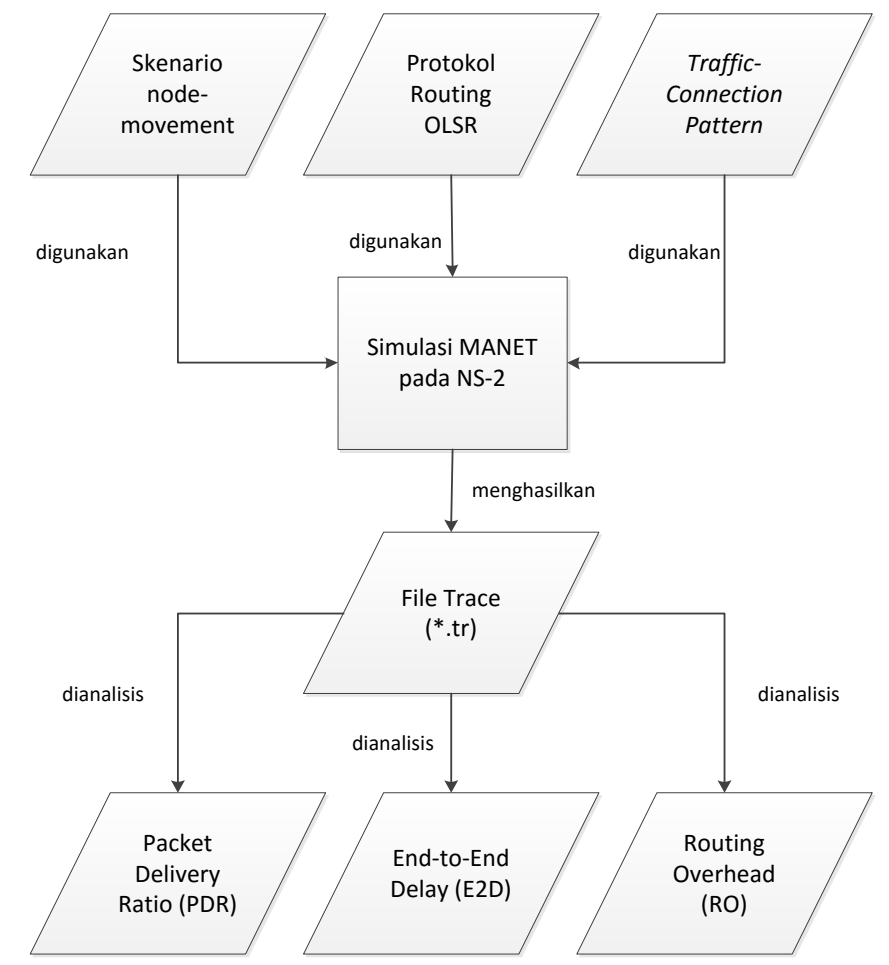

Gambar 2 Tahap Rancangan Simulasi

\section{IMPLEMENTASI}

\section{A. Implementasi Skenario}

Tabel 1

Parameter Skenario Node-Movement

\begin{tabular}{cll}
\hline \hline No. & \multicolumn{1}{c}{ Parameter } & \multicolumn{1}{c}{ Spesifikasi } \\
\hline 1 & Jumlah Node & 50 \\
2 & Waktu Simulasi & 100 detik \\
3 & Area & $510 \mathrm{~m} \mathrm{x} 510 \mathrm{~m}$ \\
3 & Kecepatan Maksimal & $-5 \mathrm{~m} / \mathrm{s}$ \\
& & $-10 \mathrm{~m} / \mathrm{s}$ \\
& & $-15 \mathrm{~m} / \mathrm{s}$ \\
5 & Sumber Traffic & $\mathrm{CBR}$ \\
6 & Waktu Jeda (dalam detik) & 10 \\
7 & Ukuran Paket & $512 \mathrm{bytes}$ \\
8 & Rate Paket & $0.25 \mathrm{paket}$ per detik \\
9 & Jumlah maksimal koneksi & 1 \\
10 & Model mobilitas yang digunakan & Random Way Point \\
\hline \hline
\end{tabular}

Tabel 2

Parameter Traffic-Connection Pattern

\begin{tabular}{clll}
\hline \hline No. & \multicolumn{1}{c}{ Parameter } & Spesifikasi \\
\hline 1 & -type cbr|tcp & CBR & \\
2 & -nn nodes & 2 & \\
3 & -s seed & 1.0 & \\
4 & -mc connections & 1 & \\
5 & -rate rate & 0.25 & \\
6 & Agent & UDP & \\
\hline \hline
\end{tabular}

Skenario mobility generation dibuat dengan men-generate file node-movement yang telah ada pada NS-2 atau tools-nya biasa disebut 'setdest' yang nantinya akan menghasilkan output dalam bentuk .txt dan digunakan dalam file Tcl selama simulasi pada NS-2 sebagai bentuk pergerakan node yang berpindahpindah.

Traffic-Connection dibuat dengan menjalankan program cbgren.tcl yang telah ada pada NS-2 yang nantinya akan menghasilkan output dalam bentuk txt dan digunakan sebagai koneksi untuk menghubungkan antar node yang ada pada skenario selama simulasi pada NS-2.

\section{B. Implementasi Network Simulator 2}

Pada implementasi kode NS-2 dengan konfigurasi MANET, dilakukan penggabungan skenario mobilitas dan trafficconnection dengan skrip TCL yang diberikan parameterparameter untuk membangun percobaan simulasi MANET pada NS-2. Berikut parameter simulasi perancangan sistem MANET yang dapat digunakan dapat dilihat pada Tabel Parameter Simulasi pada NS-2.

Tabel 3

Parameter Simulasi NS-2

\begin{tabular}{cll}
\hline \hline No. & \multicolumn{1}{c}{ Parameter } & \multicolumn{1}{c}{ Spesifikasi } \\
\hline 1 & Network simulator & NS- 2.35 \\
2 & Routing Protocol & OLSR \\
3 & Waktu simulasi & 100 detik \\
3 & Waktu Pengiriman Paket Data & - TwoRayGround $=0-$ \\
& & 100 detik \\
& & - Nakagami $=0-100$ \\
& & detik \\
5 & Area simulasi & $510 \mathrm{~m}$ x $510 \mathrm{~m}$ \\
6 & Banyak node & 50 \\
7 & Radius transmisi & $100 \mathrm{~m}$ \\
9 & Tipe koneksi & UDP \\
10 & Tipe data & Constant Bit Rate $(\mathrm{CBR})$ \\
11 & Kecepatan generasi paket & Statik (Node $1 /$ Node 2) \\
12 & Ukuran paket data & 1 paket per detik \\
\hline \hline
\end{tabular}




\begin{tabular}{rll}
\hline \hline 13 & Protokol MAC & IEEE 802.11 \\
14 & Mode Transmisi & - TwoRayGround \\
& & - Nakagami \\
15 & Tipe Antena & OmniAntenna \\
16 & Tipe Interface Queue & Droptail/PriQueue \\
17 & Tipe Peta & MANET (random way \\
& & point) \\
18 & Tipe kanal & Wireless channel \\
19 & Tipe trace & Old Wireless Format \\
& & Trace \\
\hline \hline
\end{tabular}

\section{Implementasi Metrik Analisis}

Metrik yang akan dianalisis pada Tugas Akhir ini adalah Packet Delivery Ratio (PDR), End-to-End Delay (E2D), dan Routing Overhead (RO). PDR dihitung dari perbandingan antara paket yang dikirim dengan paket yang diterima. PDR dihitung dengan menggunakan persamaan Error! Reference source not found., dimana received adalah banyaknya paket data yang diterima dan sent adalah banyaknya paket data yang dikirimkan.

$$
P D R=\frac{\text { received }}{\text { sent }} \times 100
$$

E2D dihitung dari rata-rata delay antara waktu paket diterima dan waktu paket dikirim. E2D dihitung dengan menggunakan persamaan Error! Reference source not found., dimana $t_{\text {received[i] }}$ adalah waktu penerimaan paket dengan urutan / id ke$\mathrm{i}, \mathrm{t}_{\text {sent[i] }}$ adalah waktu pengiriman paket dengan urutan / id ke-i, dan sent adalah banyaknya paket data yang dikirimkan.

$$
E 2 D=\frac{\sum_{i \leq s e n t}^{i=0} t_{\text {received }[i]}-t_{\text {sent }[i]}}{\operatorname{sent}}
$$

Routing Overhead adalah jumlah paket kontrol routing yang ditransimisikan per data paket yang terkirim ke tujuan selama simulasi terjadi. RO dihitung berdasarkan jumlah paket routing yang ditransmisikan. Baris yang mengandung routing overhead pada trace file ditandai dengan paket yang bertipe send (s) / forward (f) dan terdapat header paket dari protokol OLSR.

\section{PENGUJIAN DAN EVALUASI}

Lingkungan pengujian sistem pada pengerjaan artikel ini dilakukan pada lingkungan dan alat kakas sebagai berikut:

$\checkmark$ Processor Inter(R) Core(TM) i5-2450 CPU @ 2.50 GHz.

$\checkmark$ Sistem operasi Ubuntu 10.04 LTS 64-bit.

$\checkmark$ Memori 4GB DDR3.

$\checkmark$ Media penyimpanan 500GB.

$\checkmark$ Network Simulator 2.35.

$\checkmark$ OLSR versi 1.0.

Trace file hasil menjalankan program skenario nodemovement (mobility generation) menggunakan model transmisi TwoRayGround dan Nakagami kemudian dianalisis nilai PDR, End-toEnd Delay dan Routing Overhead-nya melalui script pdr.awk. Hasil tiap perhitungan PDR skenario ditabulasikan dan dirata-ratakan menjadi seperti pada Tabel 4 berikut:
Tabel 4

Nilai PDR Skenario Node-Movement

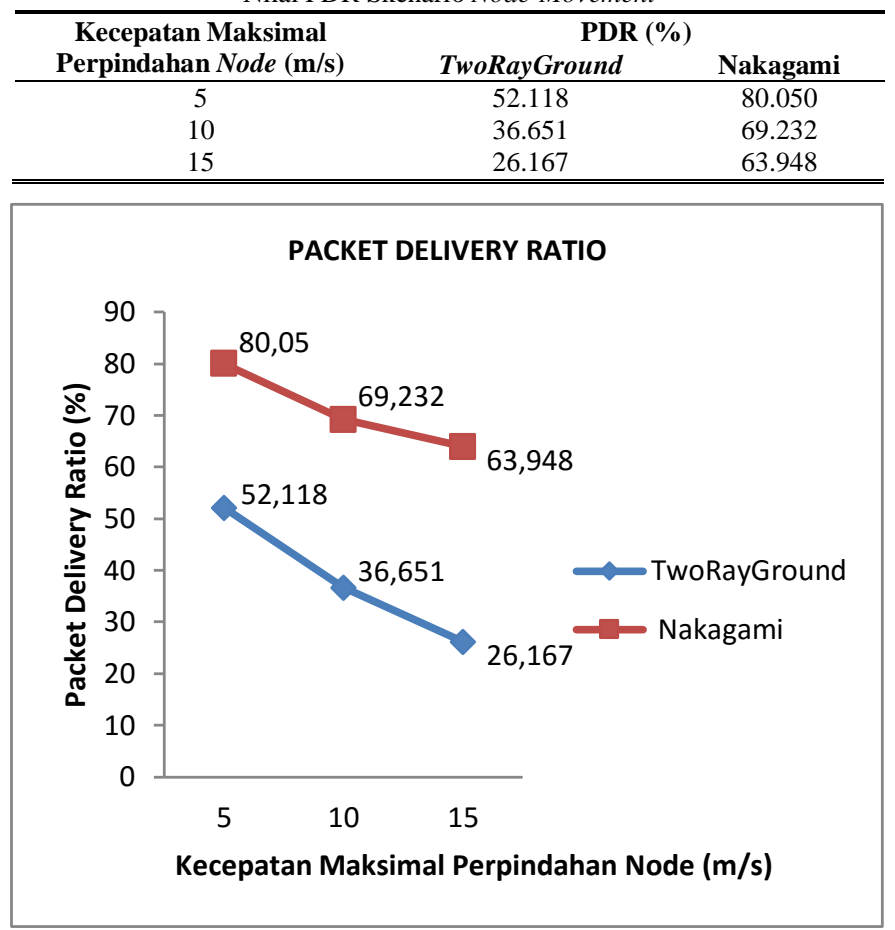

Gambar 3 Grafik PDR Skenario Node-Movement

Pada Tabel4 dan Gambar3 menunjukkan performa yang dihasilkan oleh model transmisi TwoRayGround dan Nakagami pada jaringan MANET dengan menggunakan skenario nodemovement (mobility generaion) yang bersifat Random Way Point. Terlihat bahwa PDR yang dihasilkan oleh kedua model transmisi semakin menurun dengan bertambahnya kecepatan maksimal perpindahan node.

Terlihat bahwa nilai PDR yang dihasilkan oleh model transmisi Nakagami lebih baik dan lebih stabil daripada PDR yang dihasilkan oleh model transmisi TwoRayGround pada skenario node-movement (mobility generator) MANET. Nilai PDR yang hasilkan lebih stabil pada model transmisi Nakagami dikarenakan kemampuannya untuk mengidentifikasi / memperhatikan lingkungan sekitar area simulasi dan pengaruh ketinggian antenna pada node yang ada. Tidak seperti model transmisi TwoRayGround, dari skenario yang yang dihasilkan oleh file node-movement (mobility generation) tidak mampu untuk mengidentifikasi/memperhatikan lingkungan sekitar area simulasi dan pengaruh ketinggian antenna pada node yang menyebabkan pengiriman paket antar node yang lebih cepat dan dinamis.

Kemudian untuk hasil tiap perhitungan E2D skenario ditabulasikan dan dirata-ratakan menjadi seperti pada Tabel 5.

Dapat dilihat pada Gambar 4 untuk performa End-to-End Delay pada model transmisi Nakagami memiliki nilai yang lebih baik dan lebih stabil dibandingkan dengan performa E2D yang dihasilkan oleh model transmisi TwoRayGround.

Tabel 5

Nilai E2D Skenario Node-Movement

\begin{tabular}{ccc}
\hline \hline $\begin{array}{c}\text { Kecepatan Maksimal } \\
\text { Perpindahan Node }(\mathrm{m} / \mathrm{s})\end{array}$ & TwoRayGround & E2D (detik) \\
\hline 5 & 0.023 & 0.017 \\
\hline \hline
\end{tabular}




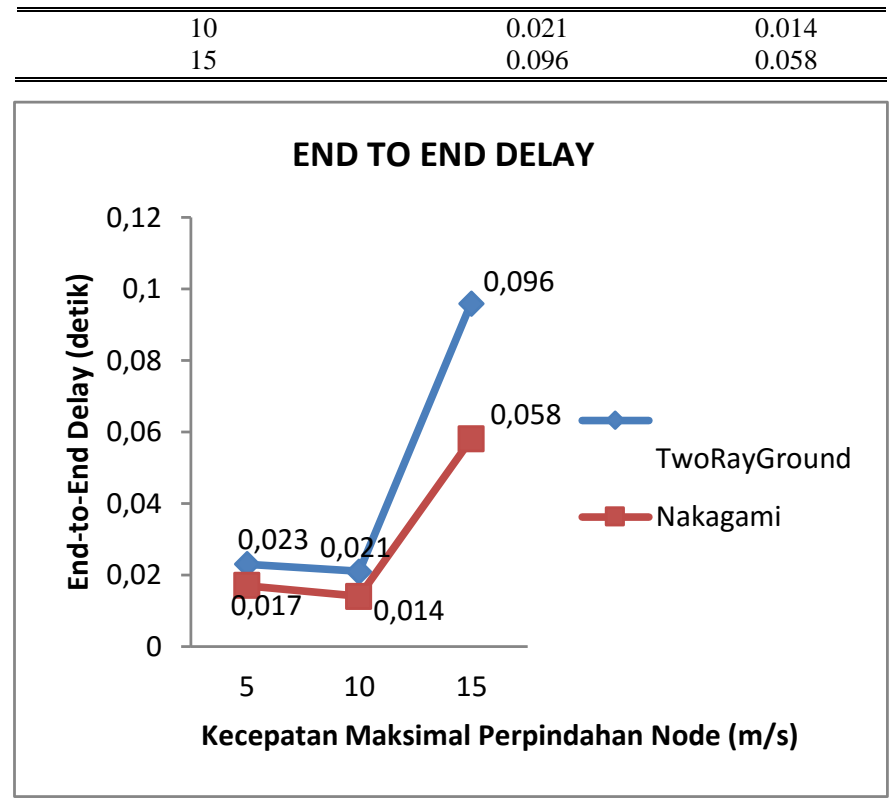

Gambar 4 Grafik E2D Skenario Node-Movement

Hal ini dapat terjadi akibat mobilitas pengiriman paket antar node yang sangat dinamis pada skenario node-movement (mobility generation) yang dihasilkan oleh model transmisi TwoRayGround. Mobilitas yang sangat dinamis ini memungkinkan terjadinya rute putus saat pengiriman paket data sehingga pengiriman paket dimasukkan ke dalam antrian dan menunggu rute baru terbentuk sebelum pengiriman paket data dilanjutkan kembali.

Sedangkan untuk hasil tiap perhitungan RO skenario ditabulasikan dan dirata-ratakan menjadi seperti pada Tabel 6.

Pada Tabel dan Gambar5 menunjukkan pengujian model transmisi TwoRayGround nilai Routing Overhead yang dihasilkan memiliki nilai yang fluktuatif berdasarkan penambahan kecepatan maksimal perpindahan node yang terdapat dalam simulasi.

Nilai Routing Overhead yang dihasilkan oleh model transmisi TwoRayGround memiliki nilai yang lebih besar dibandingkan dengan nilai Routing Overhead yang dihasilkan oleh model transmisi Nakagami. Hal ini terjadi karena pengiriman paket routing berjenis send maupun forward yang dihasilkan oleh TwoRayGround lebih banyak daripada Nakagami. Dengan demikian semakin banyaknya paket routing send dan forward yang dihasilkan, pengiriman paket data yang dilakukan memiliki kemungkinan yang lebih besar untuk sampai ke node tujuan.

Tabel 6

Nilai RO Skenario Node-Movement

\begin{tabular}{ccc}
\hline \hline $\begin{array}{c}\text { Kecepatan Maksimal } \\
\text { Perpindahan Node }(\mathbf{m} / \mathbf{s})\end{array}$ & $\begin{array}{c}\text { Routing Overhead (Paket) } \\
\text { TwoRayGround }\end{array}$ & Nakagami \\
\hline 5 & 9902.8 & 8012.6 \\
10 & 10802.5 & 9092.5 \\
15 & 10391.6 & 9299.2 \\
\hline
\end{tabular}

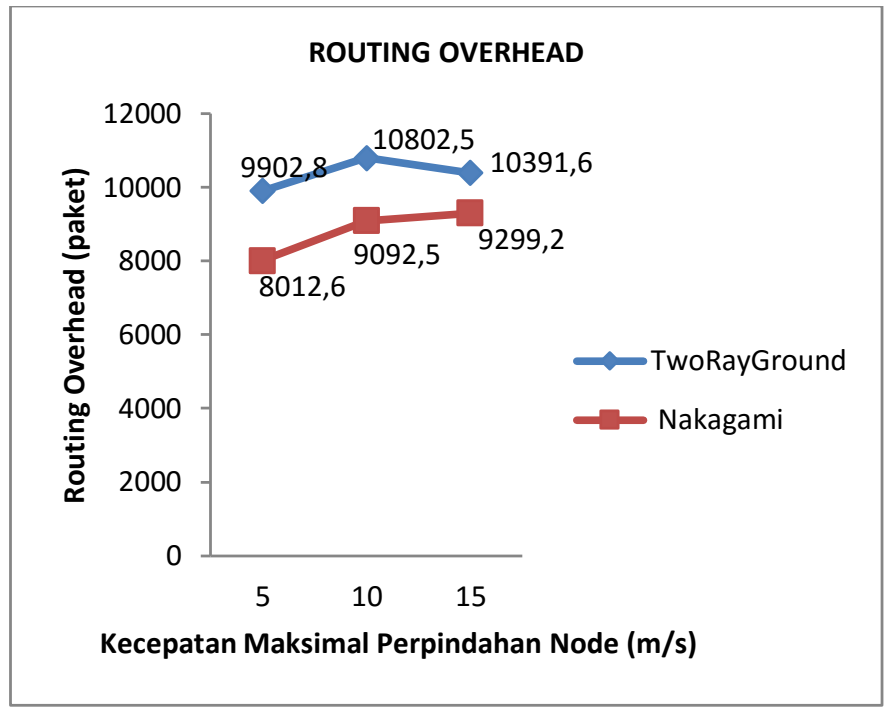

Gambar 5 Grafik RO Skenario Node-Movement

Hasil analisis yang dilakukan pada metrik-metrik diatas menyebabkan perbedaan diantara model transmisi yang digunakan, yaitu TwoRayGround dan Nakagami. Beberapa faktor yang menyebabkan terjadinya perbedaan ini mengacu pada lokasi dan pergerakan pada node.

\section{KESIMPULAN DAN SARAN}

Berdasarkan proses perancangan, implementasi, serta pengujian dapat diambil kesimpulan sebagai berikut.

1. Hal - hal yang dapat mempengaruhi nilai PDR, E2D dan RO yang dihasilkan dari model transmisi TwoRayGround dan Nakagami adalah:

- Posisi awal node yang dibuat secara acak.

- Pergerakan node yang dibuat secara acak.

- Lingkungan jaringan yang digunakan.

- Keadaan sekitar simulasi.

- Ketinggian antena.

2. Dari hasil percobaan pada skenario MANET, didapatkan nilai PDR, E2D dan RO dengan model transmisi Nakagami lebih baik dan bagus daripada nilai PDR, E2D dan RO dengan model transmisi TwoRayGround sehingga:

- Model transmisi TwoRayGround yang tidak memperhatikan keadaan sekitar simulasi dan ketinggian antena sehingga cocok untuk lingkungan MANET yang bentuk jaringannya lebih besar dan bersifat global.

- Model transmisi Nakagami yang memperhatikan keadaan sekitar simulasi seperti gedung, pohon, tanah dan obstacle-obstacle lainnya serta ketinggian antena sehingga cocok untuk lingkungan VANET karena merepresentasikan bentuk jaringannya yang lebih detail daripada MANET.

Saran yang dapat diberikan untuk pengembangan studi perbandingan kinerja model transmisi TwoRayGround dan Nakagami pada OLSR di lingkungan MANET menggunakan NS-2 adalah sebagai berikut.

1. Dapat dilakukan percobaan pada lingkungan VANET untuk penerapan kedua model transmisi yaitu TwoRayGround dan Nakagami. 
2. Dapat dilakukan pengurangan atau penambahan jumlah node dan penambahan jumlah percobaan untuk skenario node-movement (mobility generation).

3. Dapat dilakukan modifikasi pada parameter-parameter yang digunakan untuk membangkitkan uji coba MANET pada NS-2 seperti modifikasi pada parameter transmission range, modifikasi pada pause time selama waktu simulasi berlangsung.

4. Dapat dilakukan modifikasi protokol OLSR agar bersifat adaptif terhadap perubahan mobilitas node yang tinggi.

\section{DAFTAR PUSTAKA}

[1] I. N. B. Hartawan, "Optimasi Pemilihan Multi-Point Relay dengan Congestion Detection dalam Optimized Link State Routing pada Mobile Ad-Hoc Network," Digilib ITS, p. 1, 2014.

[2] M. Affandes, "3. Mobile Ad Hoc Network (MANET)," 30 October 2011. [Online]. Available: https://affandezone.wordpress.com/2011/10/30/3routing-pada-manet/. [Accessed 26 May 2016].

[3] Rechnernetze und Telematik University of Freiburg, 2011. [Online]. Available: http://archive.cone.informatik.unifreiburg.de/teaching/vorlesung/manet-s07/exercises/DSDV.ppt. [Accessed 26 May 2016].

[4] A. Saputra, "Pengetahuan Tentang Jaringan," 25 March 2009. [Online]. Available: http://de-monk.blogspot.co.id/. [Accessed 29 March 2016].

[5] Pajala, Elina, Isotalo, Tero and dkk, "An improved simulation model for Nakagami-m-m fading channels for satellite positioning applications," Finlandia, Institute of Communications Engineering Tampere University of Technology, p. 82.

[6] R. Baumann, Engineering and simulation of mobile ad hoc routing protocols for VANET on Highways and in cities, Institute of Technology Zurich, 2014. 